\title{
Obstructive Sleep Apnea (OSA) in Primary Care: Evidence-based Practice
}

\author{
J. F. Pagel, MS, MD
}

This paper presents data evidence supporting the value of diagnosing and treating obstructive sleep apnea (OSA) in reducing morbidity and mortality, improving comorbid disease processes, and improving patient quality of life. These data are derived from a PubMed-based meta-analysis of recent cost effectiveness, standards of practice, and epidemiological studies of OSA, which are ranked using a hierarchical strength of recommendation taxonomy. Cost and health care utilization data have been calculated for OSA and hypersomnolence as well as for diagnostic testing. Strong evidence (which is indicated by a strength of recommendation rating of "A") exists for the association of adult OSA with obesity, daytime sleepiness, hypertension, and motor vehicular accidents. Strong evidence also exists for requiring full-night or split-night attended polysomnography (PSG) for the diagnosis and treatment of adult OSA and for patients with systolic or diastolic heart failure not responding to optimal medical management. Good evidence (B) exists for the association of adult OSA with congestive heart failure, coronary artery disease, cerebral vascular accidents, metabolic syndrome, and increased mortality. Good evidence also exists to indicate that the nonattended PSG can be used to diagnose sleep breathing disorders, that autotitration systems can be used to titrate continuous positive airway pressure (CPAP) therapy, and that the multiple sleep latency test can be used in the assessment of daytime sleepiness. (J Am Board Fam Med 2007;20:392-398.)

This year the field of sleep medicine becomes a fully accredited American Medical Association subspecialty and an area of potential subspecialization for family physicians interested in a Certificate of Added Qualification (CAQ) in sleep medicine. The field of sleep medicine has shown remarkable growth in the last decades. The number of boardcertified sleep physicians have grown from $<500$ to $>3000$ in the last 15 years. Yet the overwhelming majority of people who suffer from disorders of sleep and wakefulness are undiagnosed and untreated. The field is relatively new, with few physicians having expertise or training in the area because sleep medicine is not regularly taught in medical schools or in physician training programs.

This article was externally peer reviewed.

Submitted 20 November 2006; revised 19 February 2007; accepted 7 March 2007.

From the Rocky Mountain Sleep Disorders Center, Pueblo, CO.

Funding: None.

Conflict of interest: The author owns $\$ 10,000$ in ResMed and Respironics stocks. The author serves on the Sleepworks Medical Advisory Board.

Corresponding author: J. F. Pagel, MS, MD, Rocky Mountain Sleep Disorders Center, 1619 N. Greenwood, Suite 206, Pueblo, CO 81003.
Many practicing physicians complete training without a clear understanding of obstructive sleep apnea (OSA), the most physiologically disruptive and dangerous of the sleep-related diseases (Table 1). ${ }^{1}$ Most patients with sleep disturbance receive their medical care in the primary care setting. Life stressors, concomitant illness, and family and social structure can precipitate sleep complaints. The primary care physician often has a more complete knowledge of these factors than the polysomnographic-oriented sub-specialist. This paper presents evidence data documenting the importance of the diagnosis and treatment of OSA in reducing morbidity and mortality, improving comorbid disease processes, and improving patient quality of life in the primary care setting. These data are derived from a PubMed-based meta-analysis of recent cost effectiveness, standards of practice, and epidemiologic studies of OSA, which are ranked using a hierarchical strength of recommendation taxonomy (Table 2).

\section{OSA-The Clinical Spectrum}

Each of us spend a third of our lives asleep. Dysfunctions in this basic state lead to declines in 
Table 1. Diagnostic Criteria for Adult Obstructive Sleep Apnea (OSA)

A. At least one of the following applies:

1. The patient complains of unintentional sleep episodes during wakefulness, daytime sleepiness, unrefreshing sleep, fatigue, or insomnia.

2. The patient wakes holding his/her breath, gasping, or choking.

3. The bed partner reports loud snoring or breathing interruptions during the patient's sleep.

B. Polysomnographic recording shows the following:

1. Five or more scoreable respiratory events occur per hour. These events can include any combination of obstructive apneas, hypopneas, or respiratory-associated arousals.

2. There is evidence of respiratory effort during all or a portion of each respiratory event.

C. This disorder is not better explained by another sleep, medical, or psychiatric disorder, substance abuse, or medication.

D. Associated features

snoring

obesity

systemic hypertension

pulmonary hypertension

congestive heart failure

sleep fragmentation

recurrent awakening from sleep

sleep-related cardiac dysrhythmias

nocturnal angina

gastroesophageal reflux

impaired quality of life

impaired concentration

diabetes

metabolic syndrome

The individual must fulfill A, B, and C. ${ }^{1}$

quality of life, diminished waking performance, more frequent illness, and increases in both morbidity and mortality. In the medical care setting, sleep disorders are common. Although $30 \%$ of the general population report symptoms of sleep disruption, $>50 \%$ of primary care patients have sleep complaints. ${ }^{3}$ Despite the high prevalence of sleep disorders in the population and primary care setting, sleep complains are often underaddressed by physicians.

OSA occurs secondary to the obstruction of the airway during sleep, resulting in continued breathing effort with diminished airflow. OSA occurs at a high frequency in the primary care clinic population. It is one of the most physiologic disruptive and dangerous of sleep-related diagnoses, affecting 1 of every 5 adults in some populations. ${ }^{4}$ As many as 18 million Americans suffer from sleep apnea. It is more common among men and those who snore, are overweight, have high blood pressure, or have physical abnormalities in their upper airways. ${ }^{4,5}$ General population studies suggest that snoring and daytime sleepiness are present in at least $4.1 \%$ of people over 40 years of age, with associated apnea diagnosed and treated in only $0.6 \%$ of this population. ${ }^{6}$

A large multicenter trial called the Sleep Heart Health Study has been designed to study the prospective effects of OSA on a large population included in previously developed cardiovascular studies (6440 men and women over 40 years of age). ${ }^{5}$ Cross-section analysis data from this study has emphasized the significant contribution of OSA to pulmonary, cardiac, endocrine, and cognitive disease. ${ }^{7-10}$ Prospective data from this study will address these factors as well as the morbidity, comorbidity, and mortality associated with OSA that have been demonstrated in multiple retrospective studies.

Table 2. Evidence-based Medicine Ratings Based on Strength of Recommendation Taxonomy ${ }^{2}$

\begin{tabular}{lcc}
\hline Strength of Recommendation & Quality of Evidence & $\begin{array}{c}\text { Consistency of Evidence Across } \\
\text { Studies }\end{array}$ \\
\hline $\begin{array}{l}\text { A. Recommendation based on } \\
\text { consistent good quality patient- } \\
\text { oriented evidence }\end{array}$ & $\begin{array}{c}\text { Good quality patient-oriented evidence- } \\
\text { validated meta-analysis or high-quality } \\
\text { or prospective cohort studies } \\
\text { Meta-analysis of lower quality or studies } \\
\text { with inconsistent findings, retrospective } \\
\text { cohort and case control studies with } \\
\text { good follow up }\end{array}$ & $\begin{array}{c}\text { Consistent-most studies with similar } \\
\text { results or supportive high-quality } \\
\text { meta-analysis }\end{array}$ \\
$\begin{array}{l}\text { inconsistent or limited quality } \\
\text { patient-oriented evidence }\end{array}$ & $\begin{array}{l}\text { Consensus guidelines, usual practice, } \\
\text { disease-oriented evidence, case series of }\end{array}$ & $\begin{array}{c}\text { Inconsistent-variation among study } \\
\text { findings or lack of coherence of } \\
\text { meta-analysis in favor of the } \\
\text { r. Recommendation based on } \\
\begin{array}{l}\text { consensus, usual practice, opinion, } \\
\text { disease-oriented evidence or case } \\
\text { studies of diagnosis, prevention or } \\
\text { screening }\end{array}\end{array}$ \\
\hline
\end{tabular}


Table 3. Evidence-based Associations of Obstructive Sleep Apnea (OSA)

\begin{tabular}{|c|c|c|}
\hline OSA Type & Associated Morbidity & Ranking \\
\hline \multirow[t]{11}{*}{ Adult OSA } & Obesity & A-consistent systemic meta-analyses ${ }^{4,5}$ \\
\hline & Cognitive impairment (daytime sleepiness) & A-consistent systemic meta-analyses ${ }^{5,7}$ \\
\hline & Motor vehicular accidents & A-consistent systemic meta-analyses ${ }^{12,13}$ \\
\hline & Hypertension & $\begin{array}{l}\text { A-cross-sectional analysis of prospective cohort } \\
\text { studies, consistent systemic meta-analyses }{ }^{10,14}\end{array}$ \\
\hline & Increased mortality & B-retrospective cohort studies ${ }^{8,12}$ \\
\hline & Congestive heart failure (right and left sided) & $\begin{array}{l}\text { B-cross-sectional analysis of prospective cohort } \\
\text { studies, inconsistent systemic meta-analyses }\end{array}$ \\
\hline & Coronary artery disease & $\begin{array}{l}\text { B-cross-sectional analysis of prospective cohort } \\
\text { studies, retrospective diagnostic cohort study }\end{array}$ \\
\hline & Cerebral vascular accidents & $\begin{array}{l}\text { B-cross-sectional analysis of prospective cohort } \\
\text { studies, retrospective cohort study }\end{array}$ \\
\hline & Metabolic syndrome & $\begin{array}{l}\text { B-cross-sectional analysis of prospective cohort } \\
\text { studies, retrospective cohort studies } 9,18\end{array}$ \\
\hline & Diabetes & C-retrospective cohort studies ${ }^{9,18}$ \\
\hline & Cardiac arrhythmias & C-case series, usual practice ${ }^{19}$ \\
\hline \multirow[t]{6}{*}{ Pediatric OSA } & Obesity & C-retrospective cohort studies ${ }^{20}$ \\
\hline & Enuresis & C-retrospective cohort studies ${ }^{21}$ \\
\hline & Poor school performance & C-retrospective cohort studies ${ }^{20,22}$ \\
\hline & Failure to thrive & C-case series, usual practice ${ }^{22}$ \\
\hline & Learning disability & C-retrospective cohort studies ${ }^{22}$ \\
\hline & Attention deficit/hyperactivity disorder & C-inconsistent retrospective cohort studies ${ }^{21,23}$ \\
\hline
\end{tabular}

Of the sleep disorders, OSA is the best studied from a cost-effect, epidemiologic, and evidencebased perspective. The associated morbidity, mortality, comorbidities, and quality of life effects are well researched and described. Adult OSA has a long-term and clear association with obesity and daytime cognitive impairment that includes daytime sleepiness. ${ }^{5,7,11}$ Daytime sleepiness has been shown to lead to an increase in motor vehicular accidents in untreated OSA patients. OSA severity correlates in part with the number of respiratory events per hour. This is generally reported as the Apnea-Hypopnea Index (AHI), which includes the total of the number of apneas (events of breathing cessation $>10$ seconds) and hypopneas $(>30 \%$ decline in breathing effort coupled with $>4 \% \mathrm{SaO}_{2}$ desaturation and/or arousal) per hour. Subjects with an $\mathrm{AHI}>10$ have a 6.3 -fold increased risk of having a traffic accident compared with 152 casematched control with AHI $<10 .{ }^{12}$ Patients with moderate to severe OSA (AHI $>34$ ) have a 15 -fold increased risk of having a motor vehicle accident. ${ }^{13}$ Recent epidemiologic studies that have crossmatched sleep apnea evaluation with long-term prospective cardiovascular risk studies have served to point out the consistent and strong association between OSA and essential hypertension. Odds of hypertension increases with increasing severity of apnea in a graded dose-response fashion with an odds ratio of 1.27 for hypertension in the group with AHI $>30$ versus the nonapnic group with an $\mathrm{AHI}$ of $<5 .^{10,14,15}$ Research supports the association between OSA and increased mortality, congestive heart failure (both right and left sided), myocardial infarction, and cerebral vascular accidents. ${ }^{16,17}$ Cross-sectional analysis data from the Sleep Heart Health Study demonstrated the following relative odds ratios for OSA patients: congestive heart failure (2.38), stroke (1.58), and coronary heart disease (1.27). ${ }^{8}$ Evidence is increasingly clear for the association of adult OSA with diabetes and metabolic syndrome. ${ }^{9,18}$ Cardiac arrhythmias (bradycardia, atrial fibrillation, and ventricular tachycardia) are often seen in polysomnography (PSG) studies of OSA patients; however, the clinical significance and OSA association of these arrhythmias has yet to be fully studied ${ }^{19}$ (Table 3 ).

The pathophysiology and clinical presentation of pediatric OSA differs from that of adult OSA. In pediatric patients, OSA is most clearly associated with poor school performance. In first-graders performing at the bottom $10 \%$ percent of grade level, $>20 \%$ have OSA. Furthermore, the grades of all children who had surgery (tonsillectomy and ade- 
noidectomy) improved, whereas the grades of children who did not have surgery showed no change. ${ }^{20}$ Studies also support the association of pediatric OSA with failure to thrive, enuresis, and learning disability. ${ }^{22}$ Studies have been contradictory in addressing the association of pediatric OSA with obesity and attention deficit/hyperactivity disorder, with strong associations occurring in specific patient populations and not in other clinically defined settings ${ }^{21}$ (Table 3).

\section{OSA Cost and Health Care Use}

The costs of untreated sleep apnea have been addressed in several studies. In 238 consecutive OSA patients studied in 1999, the mean annual medical cost was $\$ 2720$ greater per patient before diagnosis compared with age-, body mass index-, and gendermatched controls. ${ }^{23}$ Patients with OSA use health care resources at higher rates than control subjects for years before diagnosis. ${ }^{24}$ For the 10 years before diagnosis, physician claims for patients eventually diagnosed with OSA are twice (\$3972 per patient) that of age-matched controls ( $\$ 1969$ per patient). ${ }^{25}$ Of all comorbid diagnoses, significantly increased health care use is found for cardiovascular disease and hypertension in OSA patients. ${ }^{19}$ There was a rise in health care costs each year before diagnosis, with initial data suggesting that after diagnosis, yearly claims were halved. By the time patients were finally diagnosed with sleep apnea, they had already been heavy users of health services for several years. ${ }^{26}$ In Canada, hospital stays are 1.27 days per patient per year 1 year before OSA diagnosis and 0.53 days per patient per year 1 year after diagnosis. These differences were only seen in those patients adhering to treatment with no difference between patients and controls for nonadherers. ${ }^{27}$ In pediatric OSA, there are also suggestions for increased health care use with a $226 \%$ increase in health care use 1 year before evaluation, more hospital days, more drug use, and more visits to ER, with the severity of OSA correlating directly to total annual cost independent of age. ${ }^{28}$

\section{Effectiveness of CPAP Therapy for OSA}

A meta-analysis of applicable studies demonstrated that consistent evidence exists showing that treatment of OSA with continuous positive airway pressure (CPAP) therapy leads to significant improvement in daytime sleepiness and quality of life measures as well as reduced diastolic and systolic blood pressure. ${ }^{29}$ In OSA patients, there is reduced hospitalization with cardiovascular and pulmonary disease in OSA patients on nasal CPAP treatment. $^{27,29}$ CPAP treatment reduces the need for acute hospital admission due to cardiovascular and pulmonary disease in patients with OSA. For the 2 years before and 2 years after CPAP use in CPAP users, 413 hospital days were used before treatment and 54 hospital days were used after treatment. In OSA CPAP nonusers, 137 hospital days were used before treatment and 188 hospital days were used after treatment. This reduction of concomitant health care consumption should be taken into consideration when assessing the cost-benefit evaluation of CPAP therapy.

\section{Hypersomnia}

In our modern, fast-paced world, an adequate level of alertness is required for well-being and performance. In a year 2000 United States national survey, $32 \%$ of respondents reported daytime sleepiness despite adequate sleep the preceding night. ${ }^{30}$ This diagnostic category includes a group of diagnoses sharing the primary characteristic of inducing significant daytime sleepiness. These diagnoses have significant affects on waking performance and therefore morbidity and mortality. The National Health and Safety Administration in 1999 estimated that $1.5 \%$ of 100,000 police-reported crashes and $4 \%$ of all traffic crash fatalities involved drowsiness and fatigue as principal causes. Beyond the personal and social loss associated with these accidents, the National Health and Safety Administration in 1994 estimated cost at $\$ 83,000$ per fatality, resulting in a total cost of $\$ 12.5$ billion, with $85 \%$ of this cost being from workplace loss and loss of productivity. ${ }^{31}$

\section{Diagnostic Evaluation of OSA}

To diagnosis and manage OSA, sleep physicians routinely use diagnostic tests that require the sleep laboratory for evaluation of the patient. The sleeprelated breathing disorders generally require PSG for evaluation. PSG is the recording of multiple physiologic signals during sleep. The standard PSG recording montage includes channels of electroencephalography, electrooculography, and chin electromyography that are required for sleep staging as well as recordings of respiratory effort, airflow, 


\begin{tabular}{|c|c|c|}
\hline Sleep Testing & Ranking & Basis for Ranking \\
\hline \multicolumn{3}{|l|}{ Full attended polysomnography indications: } \\
\hline a) The diagnosis of sleep-related breathing disorders & A & Standard of care ch-34 $^{32-3}$ \\
\hline b) Positive airway pressure titration & A & Standard of care ${ }^{32-34}$ \\
\hline $\begin{array}{l}\text { c) Pre- and postoperative evaluation of patients } \\
\text { having surgery for obstructive sleep apnea }\end{array}$ & A & Standard of care $^{32-34}$ \\
\hline $\begin{array}{l}\text { d) Evaluation of patients being treated for OSA } \\
\text { with persistent symptoms }\end{array}$ & A & High quality cohort studies ${ }^{32-34}$ \\
\hline $\begin{array}{l}\text { e) Patients with systolic or diastolic heart failure not } \\
\text { responding to optimal medical management }\end{array}$ & A & Prospective diagnostic cohort studies ${ }^{8}$ \\
\hline $\begin{array}{l}\text { Split-night attended polysomnography for the } \\
\text { diagnosis and treatment of sleep-related breathing } \\
\text { disorders }\end{array}$ & A & Prospective diagnostic cohort studies ${ }^{32}$ \\
\hline $\begin{array}{l}\text { Treatment with PAP systems leads to reduced } \\
\text { symptoms of sleepiness, increased quality of life, and } \\
\text { lower blood pressure }\end{array}$ & A & Meta-analysis of retrospective cohort studies ${ }^{29}$ \\
\hline $\begin{array}{l}\text { Nonattended polysomnography (PSG) for the } \\
\text { diagnosis of sleep-related breathing disorders }\end{array}$ & $\mathrm{B}$ & $\begin{array}{l}\text { Retrospective cohort and case control studies } \\
\text { with good follow up }\end{array}$ \\
\hline $\begin{array}{l}\text { Limited PSG for the diagnosis of sleep-related } \\
\text { breathing disorders }\end{array}$ & - & Opinion and lower initial procedure $\operatorname{cost}^{35,36}$ \\
\hline Auto-titrating PAP for treating obstructive sleep apnea & B & Case control studies with good follow up ${ }^{37}$ \\
\hline \multicolumn{3}{|l|}{ Multiple sleep latency testing indications: } \\
\hline a) Assessing daytime sleepiness & $\mathrm{B}$ & $\begin{array}{l}\text { Meta-analysis, usual practice, usual practice, } \\
\text { disease oriented evidence }\end{array}$ \\
\hline $\begin{array}{l}\text { Maintenance of Wakefulness Testing to assess daytime } \\
\text { sleepiness }\end{array}$ & $\mathrm{C}$ & Disease oriented evidence, usual practice ${ }^{38}$ \\
\hline
\end{tabular}

pulse oximetry, snoring, sleep position, electrocardiogram, leg electromyography, and video monitoring. Additional channels are sometimes used including end-tidal or transcutaneous $\mathrm{CO}_{2}$ and additional electroencephalography channels if potential nocturnal seizure disorders are being evaluated. In evaluating the sleep-related breathing disorders, a split-night protocol is often used in which a therapeutic treatment or "titration" portion of the PSG is added after at least 120 minutes of diagnostic sleep time. During the titration, CPAP, Bi-PAP, and oxygen are used in an attempt to eliminate or reduce respiratory events and restore normal sleep. The PSG report is scored by a sleep technologist and interpreted by a sleep medicine physician. The PSG interpretation that the patient receives should include data regarding sleep architecture, respiratory parameters, periodic limb movements, a description of any parasomnia or seizure activity, electrocardiogram abnormalities, and the results of and appropriate setting of any titration attempted during the night of study.

Daytime sleepiness is generally evaluated via multiple sleep latency testing (MSLT) that includes 4 to 5 opportunities to nap in the sleep laboratory after a full night PSG under standard conditions with electroencephalography, electrooculography, and electromyography monitored so that sleep and rapid eye movement sleep onset can be determined. MSLT reports should include average or mean latency to sleep and the number of sleep onset rapid-eye-movement sleep periods recorded (a diagnostic criterion for narcolepsy). The maintenance of wakefulness test (MWT) is similar to the MSLT; however, for this procedure, the patient attempts to maintain wakefulness while monitored for appropriate testing periods to assess the patients ability to maintain wakefulness during the day.

Sleep laboratory testing can be expensive, and alternative approaches have been attempted. At this point, however, in-laboratory, full PSG with respiratory titration as required is the most cost-effective approach to evaluation of sleep disorders when required (Table 4). Limited PSGs include fewer recording channels and cannot determine whether the patient is actually asleep during the recording. Full home PSGs are a potential alternative, however, incomplete recordings are obtained in $20 \%$ of studies and titration cannot be attempted in the night of study. ${ }^{35,36}$ Auto-titrating PAP systems have minimal diagnostic capacity and can report inappropriate settings for misdiagnosed patients, 
Table 5. Summary of Evidence Based on Strength of Recommendation Taxonomy

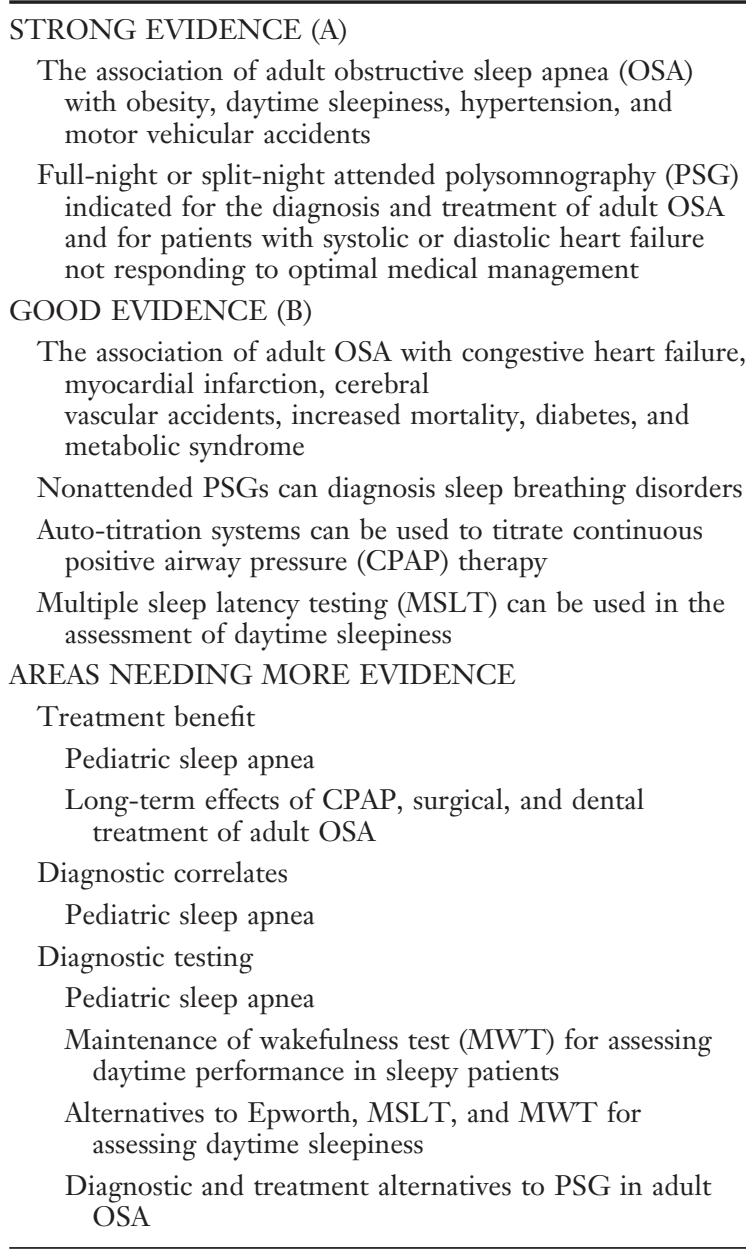

for patients with central apneas, and for those with nasal congestion or mouth leaks on CPAP therapy. ${ }^{37}$ Polysomnographic testing provides a wealth of useful information for the primary care physician involved in the treatment of the patient's sleep disorder. The primary care physician able to understand the data and interpretation from a highquality PSG will find much information useful in patient care.

\section{SUMMARY}

The evidence basis is excellent in supporting the importance the diagnosis and treatment of OSA in adults. Although data exists documenting appropriate approaches to pediatric apnea and hypersomnolence, a greater number of larger and betterdesigned studies are needed to support both diagnostic and therapeutic approaches (Table 5). The diagnosis and treatment of OSA should be considered as part of the management of diabetes, hypertension, and congestive heart failure-core aspects of primary care medicine. Sleep laboratory testing can be used as an objective insight into the patient's pulmonary, cardiac, neurological, endocrine, cognitive, and psychiatric status. The family physician with training in sleep and an understanding of appropriately used testing procedures can use current evidence based knowledge in the field to provide high-quality sleep medicine in a primary care setting.

\section{References}

1. American Academy of Sleep Medicine. International Classification of Sleep Disorders: Diagnostic and Coding Manual. 2nd ed. Westchester, IL: American Academy of Sleep Medicine; 2005. p. 51-5.

2. Ebell MH, Siwek J, Weiss BD, et al. Strength of recommendation taxonomy (SORT): a patient-centered approach to grading evidence in the medical literature. Am Fam Physician 2004;69:549-57.

3. National Institutes of Health State of the Science Conference Statement. Bethesda, MD; 2005 Aug 18.

4. Young T, Peppard PE, Gottlieb DJ. Epidemiology of obstructive sleep apnea: a population health perspective. Am J Respir Crit Care Med 2002;165(9): 1217-39.

5. Young T, Shahar E, Nieto F, et al. Predictors of sleep-disordered breathing in community-dwelling adults: the Sleep Heart Health Study. Arch Intern Med 2002;162(8):893-900.

6. Kapur V, Strohl K, Redline S, Iber C, Oconnor G, Nieto J. Underdiagnosis of sleep apnea syndrome in U.S. Communities. Sleep Breath 2002;6(2):49-54.

7. Quan S, Wright R, Baldwin C, et al. Obstructive sleep apnea-hypopnea and neurocognitive function in the Sleep Heart Health Study. Sleep Med 2006; 7(6):498-507.

8. Shahar E, Whitney C, Redline S, et al. Sleep disordered breathing and cardiovascular disease: cross sectional results of the Sleep Heart Health Study. Am J Respir Crit Care Med 2001;163(1):19-25.

9. Punjabi N, Shahar E, Redine S, Gottlieb D, Givelber R, Resnick H. Sleep-disordered breathing, glucose intolerance and insulin resistance: the Sleep Hearth Health Study. Am J Epidemiol 2004;160:521-30.

10. Nieto F, Young T, Lind B, et al. Association of sleep disordered breathing, sleep apnea and hypertension in a large community based study. JAMA 2000;238:1829-36.

11. Gami AS, Caples SM, Somers VK. Obesity and obstructive sleep apnea. Endocrinol Metab Clin North Am 2003;32(4):869-94.

12. Teran-Santos J, Jimenez-Gomez A, CorderoGuevara J. The association between sleep apnea and the risk of traffic accidents. Cooperative Group Bur- 
gos-Santander. N Engl J Med 1999;340 Suppl 11:84751.

13. Horstmann S, Hess C, Bassetti C, Gugger M, Mathis J. Sleepiness-related accidents in sleep apnea patients. Sleep 2000;23(3):383-9.

14. Richert A, Ansarin K, and Baran AS. Sleep apnea and hypertension: pathophysiologic mechanisms. Semin Nephrol 2002;22(1):71-7.

15. Smith R, Ronald J, Delaive K, Walld R, Manfreda J, Kryger $M$. What are obstructive sleep apnea patients being treated for prior to this diagnosis? Chest 2002; 121:164-172.

16. Wolk R, Shamsuzzaman AS, Somers VK. Obesity, sleep apnea, and hypertension. Hypertension 2003; 42(6):1067-74.

17. Kenchaiah S, Narula J, Vasan RS. Risk factors for heart failure. Med Clin North Am 2004;88(5):1145-72.

18. Vgontzas AN, Bixler EO, and Chrousos GP. Metabolic disturbances in obesity versus sleep apnea: the importance of visceral obesity and insulin resistance. J Intern Med 2003;254(1):32-44.

19. Verrier R, Josephson M. Cardiac arrhythmias and sudden death during sleep. In: Lee-Chiong $T$, editor. Sleep: a comprehensive handbook. Hoboken, NJ: Wiley-Liss; 2006. p. 727-32.

20. Gozal D. Sleep-disordered breathing and school performance in children. Pediatrics 1998;102:616-20.

21. Pagel JF, Snyder S, Dawson D. Obstructive sleep apnea in sleepy pediatric psychiatry clinic patients: polysomnographic and clinical correlates. Sleep Breath 2004;8(3):125-31.

22. Chervin R, Archbold K, Panachi P, Pituch K. Sleep problems seldom addressed at two general pediatric clinics. Pediatrics 2001;107(6):1375-80.

23. Kapur V, Blough DK, Sandblom RE, et al. The medical cost of undiagnosed sleep apnea. Sleep 1999;22 Suppl 6:749.

24. Banno K, Manfreda J, Walld R, Delaivie K, Kryger M. Healthcare utilization in women with obstructive sleep apnea syndrome two years after diagnosis and treatment. Sleep 2006;29(10):1307-11.

25. Ronald J, Delaive K, Roos L, Manfreda J, Bahammam A, Kryger M. Health care utilization in the 10 years prior to diagnosis in obstructive sleep apnea syndrome patients. Sleep 1999;22(2):225-235.

26. Bahammam A, Delaive K, Ronald J, Manfreda J, Roos L, Kryger MH. Health care utilization in males with obstructive sleep apnea syndrome two years after diagnosis and treatment. Sleep 1999;22 Suppl 6:740-7.

27. Peker Y, Hedner J, Johansson A, Bende M. Reduced hospitalization with cardiovascular and pulmonary disease in obstructive sleep apnea patients on nasal CPAP treatment. Sleep 1997;20:645-53.

28. Tarasiuk A, Simon T, Tal A, Reuveni H. Adenotonsillectomy in children with obstructive sleep apnea syndrome reduces health care utilization. Pediatrics 2002;110:68-72.

29. Giles T, Lasserson T, Smith B, White J, Wright J, Cates C. Continous positive airways pressure for obstructive sleep apnoea in adults. Cochrane Database Syst Rev 2006(1);CD001106.

30. Albarrak M, Banno K, Sabbagh A, Delaivie K, Walld R, Manfreda J, Kryger M. Utilization of healthcare resources in obstructive sleep apnea syndrome: a 5 year follow-up study in men using C-pap. Sleep 2005;28(10):1306-11.

31. National Sleep Foundation. Sleepiness in America: a national survey of US adults. Princeton, NJ: The Gallup Organization; 1997.

32. Chesson AL, Ferber RA, Fry JM, et al. The indications for polysomnography and related procedures. Sleep 1997;20:423-85.

33. Chesson A, Ferber R, Fry J, et al. Practice parameters for the indications for polysomnography and related procedures. Polysomnography Task Force, American Sleep Disorders Association Standards of Practice Committee. Sleep 1997;20(6):406-22.

34. Kushida CA, Littner MR, Hirshkowitz M, et al. Practice parameters for the use of continuous and bilevel positive airway pressure devices to treat adult patients with sleep-related breathing disorders. Sleep 2006;29(3):375-80.

35. Ferber R, Millman R, Coppola M, et al. Portable recording in the assessment of obstructive sleep apnea. ASDA standards of practice. Sleep 1994;17(4): 378-9.

36. Thorpy M, Chesson A, Ferber R, et al. Practice parameters for the use of portable recording in the assessment of obstructive sleep apnea. Standards of Practice Committee of the American Sleep Disorders Association. Sleep 1994;17(4):372-7.

37. Littner M, Hirshkowitz M, Davila D, et al. Practice parameters for the use of auto-titrating continuous positive airway pressure devices for titrating pressures and treating adult patients with obstructive sleep apnea syndrome. An American Academy of Sleep Medicine report. Sleep 2002;25(2):143-7.

38. Littner MR, Kushida C, Wise M, et al. Practice parameters for clinical use of the multiple sleep latency test and the maintenance of wakefulness test. Sleep 2005;28(1):113-21. 